\title{
Retraction: Coco D, Leanza S. Laparoscopic Cholecystectomy (LC): Toward Zero Error. Open Access Maced J Med Sci. 2020 May 28; 8(F):52-57. https://doi.org/10.3889/oamjms.2020.3791
}

\author{
Mirko Spiroski* \\ Scientific Foundation SPIROSKI, Skopje, Republic of Macedonia
}

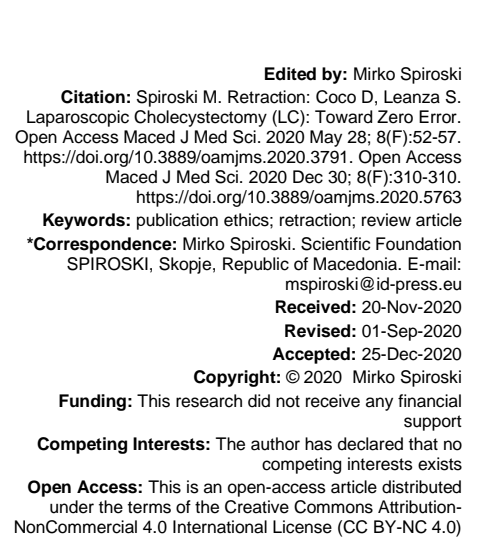

\begin{abstract}
Editor-in-Chief has retracted the article Coco D, Leanza S. Laparoscopic Cholecystectomy (LC): Toward Zero Error. Open Access Maced J Med Sci. 2020 May 28; 8(F):52-57. We received a copy of the letter from Dr Vishal Gupta, MS, MCh, FACS and Dr Gaurav Jain sent to Dr Coco. They draw our attention to the fact that this article has taken most of its material from their review article We contacted corresponding author and he agreed to retract the published paper. As such, we retract the article from the literature and by guidelines and best editorial practices from the Committee on Publication Ethics. We apologize to our audience about this unfortunate situation.
\end{abstract}

Editor-in-Chief has retracted the article Coco D, Leanza S. Laparoscopic Cholecystectomy (LC): Toward Zero Error. Open Access Maced J Med Sci. 2020 May 28; 8(F):52-57. [1].

We received a copy of the letter from $\mathrm{Dr}$ Vishal Gupta, MS, MCh, FACS and Dr Gaurav Jain sent to $\mathrm{Dr}$ Coco: With reference to your review article published recently (Coco D, Leanza S. Laparoscopic Cholecystectomy (LC): Toward Zero Error. Open Access Maced J Med Sci. 2020 May 28; 8(F):52-57. https://doi.org/10.3889/oamjms.2020.3791), we would like to draw your kind attention to the fact that this article has taken most of its material from our review article (Gupta V, Jain G. Safe laparoscopic cholecystectomy: Adoption of universal culture of safety in cholecystectomy. World J Gastrointest Surg 2019; 11(2): 62-84. [2]. Figures 1, 2, 3, 4 and 5, including their legends have been taken directly from our article without permission. In addition, text has also been taken to a great extent with minor alterations. Infact, to our another surprise, original source of these figures and text (i.e. our article) was 3. not even cited. Please find both the articles for your reference. We are happy to see your interest in safe cholecystectomy. However, such use of copyrighted material is against the principles of publication ethics. Hence, we request you to retract this article immediately. Anticipating early positive response.

We contacted corresponding author and he agreed to retract the published paper. As such, we retract the article from the literature and by guidelines and best editorial practices from the Committee on Publication Ethics. We apologize to our audience about this unfortunate situation.

\section{References}

1. Coco D, Leanza S. Laparoscopic Cholecystectomy (LC): Toward Zero Error. Open Access Maced J Med Sci. 2020 May 28; 8(F):5257. https://doi.org/10.3889/oamjms.2020.3791

2. Gupta V, Jain G. Safe laparoscopic cholecystectomy: Adoption of universal culture of safety in cholecystectomy. World J Gastrointest Surg 2019; 11(2): 62-84. https://dx.doi.org/10.4240/wjgs.v11.i2.62 